\title{
“EL OUE MATA TIENE QUE MORIR". El discurso de la mano dura en la Argentina actual ${ }^{*}$
}

\author{
Hernán Fair** \\ Recibido: 20 de abril de 2010. Aceptado: 14 de mayo de 2010.
}

\begin{abstract}
RESUMEN
El trabajo analiza críticamente el nuevo discurso emergente de la inseguridad en Argentina a partir de la noción de biopolítica de Michel Foucault. Según sostiene, el éxito de este tipo de discurso se debe a que ha logrado constituirse en un nuevo sentido común. Para ello, ha contado con la ayuda de argumentos reduccionistas y un marco sociocultural que potencia su fuerza.
\end{abstract}

Palabras clave: inseguridad, discurso, "mano dura", biopolítica, Argentina. 


\title{
"HE WHO KILLS, MUST DIE." \\ The discourse of the strong hand in present Argentina
}

\begin{abstract}
The article analyzes the new emergent discourse of insecurity in Argentina from the notion of bio-politics of Michel Foucault. According to him, the success of this type of discourse is due to the fact that it has managed to constitute itself in a new common sense. To that effect, it has counted with the help of reductionist arguments and a socio-cultural frame which power its force.
\end{abstract}

Key words: Insecurity, Discourse, "strong hand", Bio-politics, Argentina. 
Donde hay una sociedad de normalización, donde hay un poder que es, al menos en su toda su superficie, en primer instancia, en primera línea, un biopoder, pues bien, el racismo es indispensable como condición para poder dar muerte a alguien, para poder dar muerte a los otros

MICHEL FOUCAULT,

Defender la sociedad, FCE, Bs. As.

\section{INTRODUCCIÓN}

En los últimos meses ha retornado con fuerza en Argentina el tema de la inseguridad social, sus causas y posibles soluciones. La relevancia que adquiere este tema, que trasciende por mucho las fronteras del país ', ha llegado al punto tal que se ha convertido, según la mayoría de las encuestas, en el principal tema de preocupación nacional. Además, se encuentra actualmente en el tope de las discusiones en los foros de Internet ${ }^{2}$. En ese contexto, con la seguidilla de crímenes acontecidos en el país a comienzos del 2009, conocidos artistas, conductores de televisión, actores y una porción considerable de la llamada opinión pública, incluidos muchos de los periodistas de los grandes medios de comunicación de masas, han retornado recientemente al viejo debate político acerca de la conveniencia de aplicar la pena de muerte como remedio y solución definitiva a este grave problema. El siguiente trabajo se propone analizar críticamente el nuevo discurso emergente a partir de la noción de biopolítica de Michel Foucault. Según sostiene, el éxito hegemónico

1 Como destaca Bernardo Kliksberg, América Latina tiene la segunda mayor tasa de homicidios anuales del mundo y duplica, su vez, la que tenía en 1980 ("Inseguridad: la clave está en lograr exclusión cero", Clarín, 28/01/09). En efecto, mientras que en 1980 la tasa de homicidios era de 12,5 por cada cien mil habitantes, en la actualidad es de 25,1 por cada cien mil habitantes (Agustín Calcagno, "Desigualdad y delincuencia", Página 12, 16/03/09). En ese contexto, mediado por el discurso de los medios masivos de comunicación, no llama la atención que en varios países de la región, entre ellos la Argentina, el tema de la delincuencia y la seguridad pública se constituya en uno de los problemas más importante de la llamada opinión pública.

2 Para tener una idea, en Facebook existían, en marzo de 2009, 37 foros grupales en los que cerca de 8.000 personas discuten el tema de la pena de muerte en el país (Clarín, 08/03/09). alcanzado por este tipo de discurso de la biopolítica se debe a que ha logrado constituirse en un nuevo sentido común. Para ello, ha contado con la inestimable ayuda de argumentos de tipo reduccionista y un marco sociopolítico y cultural que, potenciado por los medios masivos de comunicación, potencia la imagen de respaldo social del mismo.

\section{2. “EL QUE MATA TIENE QUE MORIR”}

La famosa conductora de televisión argentina y ex actriz Susana Giménez ha tocado una fibra frágil del imaginario colectivo nacional al señalar recientemente que para terminar con el creciente tema de la inseguridad social, "el que mata tiene que morir". En palabras de la reconocida conductora y empresaria local, "Termínenla con la estupidez de los derechos humanos. El que mata tiene que morir. Ahora en Buenos Aires está todo mal" (Clarín, 28/02/09). Aunque luego rechazó contradictoriamente instaurar la pena de muerte, al tiempo que exigía nuevamente "mano dura" y citaba como ejemplo a Rudolph Giullani", lo que logró la ex actriz fue instalar el tema en la agenda pública. Acto seguido, diversos actores del ámbito local, periodistas y reconocidos conductores de televisión comenzaron a mostrar con diversos grados y facetas su respaldo a los dichos de la conductora de televisión y empresaria. El cantante Roberto Sánchez, conocido como "Sandro", afirmaría, por ejemplo, poco después "No seamos hipócritas, los que matan tienen que morir". Luego, seguiría el actor "Cacho" Castaña, quien se preguntara: "¿hace falta un juicio si te matan a un hijo?" y el cantante Luis Alberto Spinetta, quien, tras señalar su rechazo a la pena de muerte, agregara a continuación que "a algunos (delincuentes) habría que pegarles un tiro en la cabeza", y que "la pena de muerte la sufrís al salir a la calle" (Clarín, 08/03/09). Finalmente, cuando las aguas parecían aquietarse, vendría el turno del reconocido conductor de televisión y empresario

3 Alcalde estadounidense que aplicó la "mano dura" y la "tolerancia cero" en la ciudad de Nueva York como método para enfrentarse al tema de la inseguridad social. 
Marcelo Tinelli, quien respaldaría los dichos de la famosa conductora señalando que "En este país nadie hace nada para mejorar la seguridad; salís a la calle y te asesinan " (Clarín, 11/03/09).

En su famoso trabajo genealógico sobre el racismo, el célebre filósofo, sociólogo e historiador francés Michel Foucault (1992) señalaba que existe un vínculo estrecho entre la teoría biológica del siglo XIX y el discurso del poder que se ha mantenido presente hasta la actualidad y que consiste en una forma de biopoder caracterizada por la legitimación del dominio a partir de la teoría "evolucionista" inicialmente planteada por Charles Darwin. Así, si hasta el siglo XIX el poder de soberanía tenía la función de "hacer morir y dejar vivir", a partir de entonces se lo complementa por una nueva modalidad basada en su contrario, en tanto se busca "hacer vivir y dejar morir" (Foucault, 1992: 247-249). Desde este tipo de discurso biologicista, que se ha hecho famoso a partir de la teoría spenceriana del "darwinismo social", se ha señalado desde entonces que se debe eliminar a las razas "inferiores" como único método de garantizar la vida de la propia comunidad. En otras palabras, se afirma, tal como sería aplicado en genocidios neocolonialistas como el de Leopoldo II de Bélgica en el Congo (Zaffaroni, 2009), y como ha sido patente en el caso del discurso racista del nazismo (Zizek, 2002; Traversa, 2003), que debe aniquilarse al Otro, en este caso los judíos, ya que constituyen un "peligro biológico" que pone en cuestión a la propia especie (raza aria) (Foucault, 1992: 263-265).

El discurso político, lejos de ser un elemento superestructural que carece de relevancia teórica, como creían distintas tradiciones históricas de larga data que nos remontan a la Antigüedad, adquiere toda su importancia en estas circunstancias. En efecto, al apelarse a este tipo de metáforas nada inocentes como el "virus" o el "parásito",

4 En la misma línea, se pronunciarían también "famosos" como el actor Mike Amigorena, la actriz Moria Casan, el conductor de televisión Jorge Rial, el empresario/animador Gerardo Sofovich y el empresario Guillermo Coppola.

5 Retomamos, a partir de aquí, algunos elementos trabajados con más detalle en Fair (2009a y 2010). para dirigirse, por ejemplo, a los judíos durante el período nazi, el propio discurso contribuye, siempre bajo ciertas circunstancias sociohistóricas y culturales (en el caso del nazismo, profunda crisis socioeconómica, crisis del parlamentarismo alemán, mito de la "apuñalada por la espalda", sumado al enorme liderazgo carismático de Hitler), a resignificar la propia realidad social. En ese marco, retomando la función performativa que adquieren de forma potencial las palabras (Austin, 1998), las metáforas pierden toda su aparente inocencia y terminan contribuyendo en gran medida a legitimar políticamente el derecho a matar "en los hechos" a las razas "inferiores" para permitir, en este caso, la "supervivencia" de la propia "especie".

Se puede observar, bajo la hegemonía que adquieren estas metáforas biologicistas que buscan deshumanizar al Otro, que ya no se trata tanto, como en el análisis que realiza el propio Foucault (2003) sobre las prisiones de los siglos XVII y XVIII, de las formas y procedimientos que adquiere el Estado para vigilar, controlar y disciplinar a los cuerpos, sino que se impone ahora una nueva "tecnología no disciplinaria del poder", centrada en mayor medida en las formas de disciplinar las vidas de los hombres. Son precisamente estas formas de masificación general de la especie humana en campos como el nacimiento, la muerte, la producción y la enfermedad las que Foucault denomina la "biopolítica" (Foucault, 1992: 249-251).

En el caso de la Argentina, durante largos años ha predominado un discurso a favor del orden que terminó legitimando la represión y el disciplinamiento social. Aunque el origen del discurso racista nos remonta a Sarmiento y Alberdi, e incluso pueden hallarse resabios en el nacionalismo étnico de fines del siglo XIX (Fair, 2009a), los primeros antecedentes de aplicación de este tipo de discurso biologicista los podemos hallar en algunos de los ideólogos del Golpe de Estado de 1930, quienes acusaban a los judíos de ser "parásitos" que atentaban contra la permanencia del orden social (Lvovich, 2001). Sin 
embargo, esta lógica de disciplinamiento social por la vía del discurso biologicista de matriz biopolítica sólo alcanzaría su apogeo en la época de la última dictadura militar (1976 1983). En efecto, como lo ha puesto de manifiesto el politólogo argentino Guillermo O’Donnell (1984) en un interesante trabajo sobre el tema, durante los años 70 circulaba en los intersticios de la sociedad un tipo de discurso hegemónico que, trascendiendo la represión física proveniente desde la cima del Estado, lo que nos retrotraería solamente a la pura violencia social "desde arriba", al estilo marxista ortodoxo, señalaba de qué modo había que vestirse, presentarse ante la sociedad, pensar. Debemos tener en cuenta que no sólo desde el Estado, sino también desde algunos sectores dominantes de la propia sociedad civil, se afirmaba insistentemente que había que tener el pelo corto, estar afeitado, usar polleras o pantalones largos, estar con colores "apagados" y poco llamativos, etc. En la misma línea, circulaba en aquel entonces la famosa frase "No te metas" o "Algo habrán hecho", para culpar a las víctimas del "Terrorismo de Estado" y legitimar, así, la represión y la violencia sistemática del Estado contra los grupos "subversivos", aquellos "parásitos" que ponían en cuestión el orden social "Occidental y Cristiano" (O’Donnell, 1984; Barros, 2002).

Lo que se pone de manifiesto con la presencia de este tipo de discurso, que contribuyó, en un contexto de crisis socioeconómica, a la matanza de miles de ciudadanos que pensaban, sentían o vivían con ideas políticas contrarias a las que por entonces se señalaban como las "correctas" o "normales", de acuerdo con la "moral y las buenas costumbres" de la Argentina conservadora y reaccionaria, es la vigencia de una pluralidad de discursos y prácticas biopolíticas que, en los términos foucaultianos, tenían como fin mantener a la sociedad disciplinada y en orden. Pero, además, se puede observar que los mecanismos de disciplinamiento y control social, o de "gobernabilidad" política, como se los conoce actualmente (Murillo, 2008: 45 y ss.), no sólo dominaban mediante la pura fuerza física, tal como lo creía el marxismo tradicional, sino también mediante el consenso y la presión social coercitiva, tal como ha sido señalado tempranamente por el funcionalismo durkheimiano y analizado luego, desde un enfoque opuesto, por Gramsci (1977) y luego por Althusser (1988). Esta presión consensual se legitimaba, a su vez, en el uso de aquellas metáforas "científicas" que, al configurarse en la exclusión sistemática del Otro a partir de su deshumanización, señalaban la necesidad perentoria de eliminar como sea del seno de la sociedad a aquel "virus" que sólo podía ser dañoso para el "cuerpo social". En otras palabras, como los guerrilleros a los que se enfrentaba el Proceso eran caracterizados como un "virus", y todo virus sólo puede significar un objeto a combatir y eliminar, entonces el discurso político contribuía a deshumanizar y, de este modo, legitimar la aniquilación de ese "virus" que corrompía el "cuerpo social" de la República (Fair, 2009a, 2010).

Mediante la apelación y aplicación de este discurso claramente biopolítico se puede entender también que las formas de violencia social no sólo provinieran desde la cima del poder estatal y su burocracia organizada, sino que existieran también tendencias autoritarias, despóticas y paranoicas que circularan de manera relacional e intersticial por toda la sociedad. En efecto, como hemos señalado, y ha sido destacado por el post-estructuralismo, la semiótica social, el psicoanálisis y el pragmatismo, el discurso contribuye a constituir y, en muchos casos, a resignificar el sentido que atribuimos a la realidad social. En ese contexto, signado por la presencia de un discurso que "desde arriba" señalaba que existía un "virus" que estaba "subvirtiendo" el orden social en su conjunto, no llama la atención que en gran parte de la sociedad se constituyera un discurso paranoico que observara con agrado la necesidad de eliminar como fuera ese "virus" que estaba poniendo en "peligro" los cimientos del Orden público. Con ello no estamos negando, ni mucho menos, que durante los años 70 existiera un plan sistemático para eliminar a disidentes políticos, algo que ya fue comprobado en la Argentina con los documentos del informe "Nunca más" durante el gobierno de Alfonsín (1983-1989) y los 
archivos desclasificados del llamado Plan Cóndor, que extendería el programa de aniquilación de la "subversión marxista" en gran parte de la región. Lo que queremos decir es que la desarticulación social de la Argentina homogénea e igualitaria de la posguerra no habría sido posible sin la presencia de un particular tipo de discurso político que contribuyó a resignificar la propia realidad social y, de este modo, a legitimar políticamente el secuestro, tortura y "desaparición" de miles de personas. Precisamente, la aplicación de la lógica biopolítica fue uno de los discursos dominantes en los años 70, y es el mismo tipo de discurso, si bien matizado, que, como un síntoma social, puede hallarse en la reemergencia actual del discurso de la llamada "mano dura".

Si nos retrotraemos, entonces, al discurso en favor de la "mano dura", actualmente en boga en una parte importante de la sociedad argentina ${ }^{6}$, podemos ver su nueva configuración como mecanismo de disciplinamiento biopolítico del orden social. No obstante, a diferencia del discurso de "orden policial" (Ranciere, 1996) iniciado a mediados de la década del 70 , ya no se busca un poder dictatorial que imponga el orden social en el seno de la comunidad mediante la pura represión y eliminación de los cuerpos "indeseables". Por el contrario, en el marco del fracaso estrepitoso del Proceso, que se vio obligado a dejar el mando en 1983 en medio de una catastrófica derrota en la Guerra de Malvinas de 1982 y una profunda crisis socioeconómica que lo deslegitimó completamente, ahora se buscan nuevas formas de disciplinamiento biopolítico en el que, salvo muy contadas excepciones, se defiende expresamente al régimen democrático de gobierno. En otras palabras, en el marco

6 Cabe recordar que en los años '90, al compás del proceso de destrucción del Estado social de posguerra y la emergencia sintomática de bolsones de pobreza e indigencia, reflotó la demanda de "mano dura" por parte de diversos sectores de la sociedad. Este tipo de discurso se expresó de forma representativa en el ex Gobernador de Buenos Aires Carlos Ruckauf, quien señalaba que había que "meter bala a los delincuentes", y en el los intendentes bonaerenses Aldo Rico y Luis Abelardo Patti (ambos acusados de represión ilegal durante la última Dictadura militar). Más recientemente, emergió a través de una amplia movilización social por el asesinato de Axel Blumberg, liderada por su padre. de una aceptación extendida de la democracia como sistema institucional, no se pide ya (al menos no de manera masiva) el retorno a las Fuerzas Armadas como encargadas de recuperar y garantizar el orden hobbesiano frente al caos social, al menos no de una forma masiva, sino que se exigen cambios inmediatos y tangibles dentro del propio régimen democrático. Sin embargo, al mismo tiempo que se defiende a la democracia (en realidad, una versión formal y muy limitada de la misma), se exige nuevamente que el Estado como garante del orden soberano se haga cargo de eliminar a los delincuentes que impiden la "supervivencia" del "cuerpo social".

En ese contexto, se puede hallar la inmediata inscripción de este discurso de orden policial o biopolítico dentro del discurso evolucionista y racista del siglo XIX, y su posterior aplicación en los golpes de Estado de 1930 y 1976. En efecto, si el que "mata tiene que morir", si se trata de "un sádico que mata y remata", como lo ha denominado Susana Giménez (Clarín, 28/02/09), de lo que se trata nuevamente es de aplicar una lógica biopolítica foucaultiana en la que el Estado debe ser el encargado de eliminar por la fuerza a aquellos sectores que impiden la permanencia de la vida en sociedad. En otros términos, desde el nuevo discurso emergente, que, con la ayuda de los poderes y saberes dominantes, ha logrado conformar una nueva hegemonía de sentido común, los "delincuentes", a quienes se quita toda entidad como sujetos plenos de derecho ("los derechos humanos son sólo para los delincuentes", se afirma con insistencia), deben ser eliminados del "cuerpo social" (cara metáfora organicista), para lograr la propia "supervivencia" de la especie humana. Al igual que el "loco moral" de la psiquiatría inglesa, el "delincuente nato" de Cubi, Soler y Lombroso, el "mestizo degenerado" de Morel, o los mestizajes que neutralizaban la "raza superior" de Gobineau (Zaffaroni, 2009), al igual que en la tradicional metáfora del "parásito" que solían utilizar los nazis para referirse a los judíos, negándoles toda entidad como seres humanos (Traversa, 2003), los delincuentes son situados y estigmatizados 
como aquellos objetos extraños que impiden la continuidad de la especie y, por lo tanto, deben ser eliminados como sea de la sociedad para permitir la propia sobrevivencia del "cuerpo social" que se encuentra en peligro ${ }^{7}$.

\section{EL QUE MATA, ¿TIENE QUEMORIR?}

Señalamos anteriormente que a partir de la presencia de este tipo de discurso de tendencia racista y biologicista a favor de la pena de muerte, un discurso con largos antecedentes históricos que tiene base en el pensamiento de teóricos como Herbert Spencer y la posterior aplicación social de la ciencia "eugenésica" (Zaffaroni, 2009), se deshumaniza a los sujetos sociales, a partir de la "Ciencia", quitándoles toda entidad como pertenecientes al género humano. En ese contexto, que en nuestro país tiene también una larga historia que se remonta al discurso racista de Domingo Sarmiento $^{8}$ (Solodkow, 2005), se exige al Estado que actúe mediante una lógica biopolítica que garantice el disciplinamiento y, en última instancia, la "supervivencia" social.

En esta línea, en marzo de 2009 se realizó en Buenos Aires una masiva marcha a favor de la "mano dura" en la que la consigna principal era "Basta de inseguridad. Antes que nos maten salgamos a la calle" (Clarín, 19/03/09). Como señala de manera aprobatoria el ex juez Eduardo Gerome, este tipo de discurso, que concuerda con el último Catecismo de la Iglesia Católica argentina, de 1997, justifica la pena de muerte, ya que "la preservación del bien común de la sociedad exige colocar al agresor en estado de no poder causar perjuicio" (declaraciones en Clarín, 08/03/09). En

7 Puede observarse, de este modo, la relevancia crucial que adquieren las metáforas, una cuestión que ha sido destacada por la retórica y el psicoanálisis lacaniano y recuperada por las actuales corrientes post-estructuralistas lideradas por Laclau y Zizek.

8 No obstante, no sólo en Argentina existe una larga tradición de este tipo de discurso racista. Como señala Solodkow, existen en América Latina, además del caso de Sarmiento (181 1-1888), otros intelectuales racistas basados también en las ideas evolucionistas y positivistas de Spencer y Compte, como Euclides Da Cunha (1866-1909), Andrés Bello (1781 1 1865), José Martí (1853-1895) y Alcides Arguedas (1879-1946) (Solodwok: 2005: 96). otras palabras, se trata de legitimar la más pura lógica biopolítica de "hacer matar" para "dejar vivir".

Como señala Foucault en El orden del discurso, los mecanismos de disciplinamiento "tienden a ejercer sobre los otros discursos una especie de presión y como un poder de coacción" (Foucault, 1973: 18). En ese contexto, se hace muy difícil oponerse a ellos. Más difícil se hace aún, cuando el propio discurso se constituye en una lógica que ha logrado conformar un sentido común hegemónico. Para entender esta hegemonización del nuevo discurso biopolítico podemos destacar una pluralidad de factores. Entre ellas, su funcionalidad con toda una lógica mercantil que vive de este negociado y la espectacularidad de la que se benefician económicamente los medios masivos de comunicación a través del incremento del ráting. Además, el propio discurso mediático se caracteriza, como lo ha destacado Bourdieu, por una excesiva simplificación de los problemas existentes, dejando de lado la conexión de estos problemas con factores sociohistóricos y contextuales más generales. Por otra parte, debemos reconocer que su lógica comercial, en tanto empresas oligopólicas altamente concentradas (Mastrini y Becerra, 2006), resulta funcional y de hecho se encuentra vinculada directamente a sectores del establishment que, al igual que en los años 70, promueven la represión física de los sectores populares para favorecerse económicamente. Finalmente, no puede dejar de soslayarse que el gobierno liderado por Cristina Fernández (electa en octubre de 2007), se ha enfrentado directamente con los principales sectores del poder político-económico. En ese marco, ha promovido una activa política a favor de los derechos humanos, incluyendo el juzgamiento de genocidas que perpetraron la matanza del "virus marxista" en los 70. Además, se ha enfrentado con las empresas multimediáticas, limitando el poder oligopólico del principal conglomerado del país, el Grupo Clarín, a través de una nueva ley de democratización de medios, la estatización de la jubilación privada (donde actuaban como accionistas) y la nacionalización del fútbol codificado (donde el grupo mediático tenía una participación hegemónica). 
Sin dejar de reconocer la indudable importancia de estos factores, que han incentivado el rechazo de los medios masivos y de los sectores de la nueva derecha a todo lo que fuera asociado al Gobierno, en esta ocasión haremos mención a la dimensión específicamente sociocultural de este fenómeno. En dicho marco, debemos señalar que el discurso de la llamada "mano dura" se constituye exitosamente en su excesiva simplicidad. En efecto, desde el discurso del orden policial se simplifica en extremo el grave y multicausal problema de la inseguridad social, para hacer hincapié en sus efectos inmediatos. Al poner el énfasis en los efectos tangibles, esto es, en las muertes de decenas de ciudadanos, no se analizan en detalle las múltiples causas y condicionantes que las promovieron. Por el contrario, y de acuerdo con el discurso biopolítico dominante, estas se limitan a un discurso que suele utilizar el prejuicio "de clase" (delinquen porque son pobres y les falta educación), o directamente al tradicional racismo evolucionista (delinquen porque no aprendieron a tener consideración por el género humano, son los antiguos "bárbaros" e ignorantes sarmientinos que no aprendieron a convivir "civilizadamente" en sociedad y, por lo tanto, deben eliminarse sin piedad).

Una de las derivaciones habituales de este tipo de discurso hegemónico es exigir al Estado la "pena de muerte". Así, se parte de una especie de Estado hobbesiano signado por la "guerra civil". En ese contexto de "guerra de todos contra todos", sin embargo, no se exige un "discurso hobbesiano de superación del caos" (Aboy Carlés, 2001) que haga presente un Leviathan que garantice como fuera la recuperación del orden público. Por el contrario, se exige un orden policial, en los términos de Ranciere (1996), o bien un orden biopolítico, en palabras de Foucault (2003), en el que "el que mata tiene que morir", un discurso en el que los derechos humanos no "ayuden" sólo a los delincuentes (en particular, a los violadores seriales y asesinos reincidentes), sino a todo el "cuerpo social" que se encuentra en peligro de disolución. Como lo ha señalado Susana Giménez (y luego recibiría el apoyo de diversos artistas locales) ${ }^{9}$, se trata de "terminar con los derechos humanos para los delincuentes" (Clarín, 28/02/09). En efecto, como destaca el ex juez Eduardo Gerome, "en los casos de asesinos reincidentes, secuestradores que matan o violadores seriales, que vuelven a delinquir, como nos muestra la crónica diaria, se advierte que el poder público no puede garantizar la seguridad de la población. Entonces, ¿̇por qué se debe destinar el dinero de los contribuyentes a mantenerlos presos, a sabiendas de que al recuperar la libertad vuelven a constituirse en alarma social?" (declaraciones citadas en Clarín, 08/03/09).

En otros casos, que recuerdan de cierta forma a la teoría contractual de John Locke, se parte de la base, en cambio, de que el Estado no hace nada por detener el problema de la inseguridad, por lo que ni siquiera se exige al Estado que se haga cargo del mismo como correspondería. Directamente, como decía Locke (2000) en relación con el Estado previo a la constitución de la sociedad civil, se afirma la necesidad de "matar" por "mano propia" a los maleantes frente al estado de indefensión social y como modo de proteger la "propiedad privada" (libertad, vida y bienes personales) que se encuentra en peligro. En ese contexto pre político quizá puedan ser situadas las declaraciones del cantante "Cacho" Castaña, quien saldría a apoyar los dichos de Susana Giménez afirmando que "Si a mí me matan

9 No sólo artistas. También, como señalamos, recibiría el respaldo de diversos sectores sociales que se expresan a través de los foros de Internet. Entre muchos otros ejemplos, podemos citar el siguiente, de "Mafalda": "Acá tienen que venir leyes más fuertes y el que mata tiene que morir. Que los delincuentes tengan miedo, porque estamos en un estado de indefensión espantoso. Esto no da para más. No podemos seguir siendo tan mansos, decir 'que barbaridad' y no hacer nada"; o el de "Tato", quien señala que "Los legisladores deben de dejar de jugar a la interna y dedicarse a los temas que angustian a la gente. Por si no tienen imaginación, les doy el tema: pena de muerte para todo delito que implique muerte de víctima" (frases citadas en el Blog de Clarín "Pasión por Male": http://blogs.clarin.com/pasionpormalemirra/2009/2/27/noti-male-hablo-susana-gimenez-senti-memoria-). Otras declaraciones similares pueden verse también en "En Facebook 8 mil personas debaten sobre la pena de muerte en el país", Clarín, 08/03/09). 
a mi mujer y a mis hijos, saco una itaka y no paro de matar gente" (Clarín, 11/03/09).

El otro camino al que lleva este discurso liberal e individualista de la "mano dura", en los casos menos extremistas, es a la idea de encerrar y aislar a los delincuentes, tal como señalaba Foucault en su trabajo sobre las cárceles (Foucault, 2003). Así, en lugar de exigir la pena de muerte, se reclama al Estado que se reduzca la edad de inimputabilidad de los menores de edad (en Argentina, garantizada para menores de 18 años) hasta los 13, 11 ó 9 años, para evitar que se sigan cometiendo los "atroces" e "impunes" crímenes. Al mismo tiempo, fomentado y estimulado por parte importante del establishment económico y mediático, se exige al Estado que incremente la cantidad de años de cárcel efectiva, encerrando y castigando duramente a los delincuentes por sus actos. En este sentido, Marcelo Tinelli ha afirmado recientemente su desazón, ya que "Los delincuentes están libres. Acá te matan por el pancho y la Coca (Cola) y nadie hace nada". En ese contexto de "inacción", en el que "nadie se hace responsable de las cosas" y "el que mata no tiene castigo", el famoso conductor y empresario televisivo no exigirá defender la propiedad privada en un sentido pre pacto social lockeano, sino que se situará en un Estado contractualista exigiendo que el Estado se encargue de endurecer y cumplir las leyes para defender la propiedad privada. En sus palabras, "Nosotros no tenemos que encargarnos de esto (...) ¿Por qué tenemos que estar controlando la cuadra, la casa, el barrio? Pagamos los impuestos para que alguien vele por nosotros" (Clarín, 11/03/09).

Si en el primer caso, la lógica biopolítica es más que clara, exigiendo al Estado la eliminación lisa y llana de los delincuentes del orden social con el objeto de mantener con vida a la población (una lógica extrema del "matar para vivir"), en esta segunda opción podemos encontrar, sin embargo, nuevamente la presencia del discurso biopolítico. La (falta de) lógica sería la siguiente: como el problema son los delincuentes, la solución entonces es eliminarlos, pero ya no mediante la eliminación directa (pena de muerte), sino mediante el encie- rro por tiempo indeterminado ("mano dura"). En palabras de Susana Giménez, "Tampoco (quiero) que un sádico que mata y remata tenga un mes de 'cana' porque tiene 18, 16 o 15 años. Se necesita una mano más fuerte. Es lo que piensa todo el país" (Clarín, 28/02/09).

En ambos casos, el más extremo a favor de la pena de muerte (que incluye, además, un fuerte discurso a favor de la represión física de los maleantes), y el menos extremo a favor de la reclusión indeterminada y la reducción de la edad de la inimputabilidad de los menores de edad, opciones que, como hemos visto con el discurso de Susana Giménez, muchas veces tienden a integrarse entre sí, la lógica de la biopolítica se hace presente de todas formas. La idea, en todos los casos, es eliminar como sea del seno de la sociedad a aquellos parásitos, a aquellos delincuentes peligrosos e indeseables que, en tanto libres/vivos, ponen en peligro la permanencia y continuidad del "organismo" social. Y en todos los casos, con la excepción parcial de aquellos que prometen "venganza" por la vía personal, la solución se centra, en definitiva, en demandas directas hacia el Estado para que se encargue de hacer el trabajo de eliminar a estos "parásitos" sociales, a esos seres "infrahumanos", para permitir que la sociedad (en tanto conjunto de individuos aislados) "sobreviva" como tal. Como lo resumirá de manera elocuente el propio Marcelo Tinelli, "el derecho humano de una persona es el derecho a vivir y eso no está respetado ahora en nuestro país (...) Si me mataran a un ser querido diría lo mismo (que Susana Giménez), y yo también estoy cansado de los derechos humanos de los presos" (Clarín, 11/03/09).

Ahora bien, en lugar de analizar los efectos inmediatos de la inseguridad, ¿no sería mejor analizar en detalle sus múltiples causas y motivaciones? En lugar de pensar que los delincuentes matan porque son malos por naturaleza, o porque son sádicos que disfrutan de matar, o bien lo hacen porque no existen leyes más fuertes que los limiten (como si los delincuentes robaran o dejaran de hacerlo pensando en la cantidad de años de 
prisión que les corresponderían), ¿no sería mejor ver las causas socioeconómicas y culturales que los llevaron a esa situación ${ }^{10}$ ? Resulta evidente que existe cierta impunidad generalizada en la Justicia y en el seno de la propia dirigencia política. Sin embargo, sería muy reduccionista pensar que el único motivo que lleva a los maleantes a delinquir se debe a que las leyes son muy blandas, o bien que no tienen educación suficiente para comportarse adecuadamente. En lugar de este pensamiento simplificador, que se da la mano con el enfoque neo-institucionalista ${ }^{11}$, habría que pensar en la situación de extremo desamparo social, en el incremento de la pobreza e indigencia, en la falta de acceso a una educación como corresponde debido a su necesidad obligada de trabajar, o a la imposibilidad de obtener los recursos económicos necesarios para comprar útiles y ropa, en el gravísimo problema de las drogas y, en menor medida, del alcohol, que lleva a muchos sectores sociales, en su mayoría carenciados, a buscar por todos los medios la repetición continua de ese goce sintomático que les permita olvidar su situación de desamparo social o, en los términos lacanianos, de eludir la falta Real constitutiva, a través del consumo pulsional de estupefacientes $^{12}$. Por otra parte, se debería hacer hincapié, en una segunda instancia, en los pocos cuidados recibidos por parte de los padres, y también en el ineficiente, y muchas veces cómplice, funcionamiento actual de las instituciones (policías, jueces, fiscales, etc.), aunque sin limitar el análisis a este único particular.

10 En esta línea, el sociólogo Juan Pegoraro señala que "Hay que reconocer que hay hechos como los que suceden estos días que impactan fuerte en cualquier persona. La cuestión es cómo se interpretan esos hechos. Lo obvio, lo vulgar, es considerar al hecho separado de un cierto contexto socioeconómico, es no entender la exclusión social, la marginación, la degradación de muchos millones de personas desesperadas" (declaraciones citada en "El talión farandulero", Página 12, 15/03/09).

11 Nos referimos a aquellos sectores que señalan de manera reduccionista que la solución a todos los problemas estructurales del país y a la situación de decadencia socioeconómica que ya lleva más de tres décadas se arreglan con el simple "cumplimiento de las leyes" y la garantía de "seguridad jurídica" a los inversores.

12 Sobre el circuito de la pulsión en Lacan y su función de evitar la falta Real para acceder al goce puro del consumo de drogas, véase Sissa (1968). Hemos trabajado también este tema, en un marco más general, en Fair (2009b).
El conocido sociólogo polaco Zigmunt Bauman (2005) ha señalado en un trabajo en el que analiza este tema del "temor" al "otro", este miedo a la alteridad que representa el "enemigo interior" y la exigencia perentoria de "separarlos" o "desterrarlos" de la comunidad (Bauman: 2005: 64-65 y ss.), que realizar las preguntas adecuadas es un primer paso para hallar soluciones eficaces. En efecto, "formular las preguntas correctas constituye la diferencia entre someterse al destino y construirlo, entre andar a la deriva y viajar" (Bauman, 2005: 12). En ese contexto, entonces, resulta pertinente preguntarse de forma clara y precisa: ¿por qué no se hace hincapié en las múltiples causas y motivaciones socioeconómicas, culturales, políticas, históricas y psicológicas que llevaron y llevan a muchos individuos a delinquir, en lugar de centrarse en los simples efectos desde un enfoque reduccionista? En un plano más específico, ¿̇por qué no relacionar la creciente crisis económica y social y la reducción de las funciones de asistencia universalizada del Estado fordista-keynesiano de posguerra, junto con sus formas de socialización y contención integrada alrededor de la fábrica y el trabajo asalariado, con el incremento de los índices de delincuencia, en lugar de decir que los pobres delinquen porque saben que salen libres? En ese marco, ¿por qué no dar cuenta de la situación de desamparo y desesperación en la que se sitúan millones de niños y jóvenes que no pueden acceder a una buena educación, a servicios de salud básicos, a la asistencia social y sobre todo, a un trabajo digno ${ }^{13}$ y, por tanto, no ven otra escapatoria que abordar la delincuencia, o bien consumir la dosis de droga (en general, la droga más barata y dañina que se conoce como paco ${ }^{14}$ ), lo que los lleva, en última instancia, a delinquir para continuar consumiendo droga, en lugar de

13 Basta, sino, señalar que, según datos de Bernardo Kliksberg (citados en Clarín, 28/01/09), uno de cada cuatro jóvenes latinoamericanos están actualmente fuera del sistema educativo y del mercado de trabajo, para dar cuenta de la complejidad y multicausalidad que adquiere el fenómeno de la inseguridad social.

14 Según el especialista José Granero, Secretario de Prevención y Lucha contera el Narcotráfico, "el paco en seis meses te destruye las neuronas. Por eso viene acompañado del marketing de la muerte" ("Ponemos todo nuestro esfuerzo, pero no alcanza", entrevista en Clarín, 15/03/09). 
pedir que se los mate lisa y llanamente porque no pueden "convivir en sociedad"? Por último, ¿por qué no centrarse en las condiciones mínimas de higiene y seguridad en las que deberían vivir los presos y la prácticamente nula contención social y capacidad de integrarse al circuito económico y a insertarse a un ámbito socio-cultural en el que puedan convivir como sujetos plenos de derecho, en lugar de señalar, como suele hacerse, que los presos "entran por una puerta y salen por la otra"?

Resulta evidente que es más fácil abonar esta última opción reduccionista y simplificadora de la realidad (una opción que, además, ha fracasado en numerosos países y en reiteradas ocasiones) $^{15}$; y los grandes medios de comunicación de masas, ya sea para incrementar el rating, o bien para beneficiarse política y económicamente del desprestigio del Gobierno que ha osado limitar su poder, han ayudado en mucho a crear y profundizar este sentido común en favor de la "mano dura" y la represión social como solución "fácil" al complejo tema de la inseguridad. Basta, sino, observar la repetición constante de casos similares de inseguridad que llevan a cabo sin explicar sus múltiples causas y como si fueran situaciones no conectadas entre sí con una realidad sociopolítica y cultural más amplia. Este tema, que ha sido criticado por Bourdieu en su trabajo sobre la televisión (Bourdieu, 1997), se ve reforzado por otro de los temas abordados por el gran sociólogo francés: la "ilusión de consenso social generalizado" (Bourdieu, 1999: 18; Vega García, 1998: 29-30) que se conforma a partir de la idea de que todos los medios de comunicación masivos y las grandes figuras creadoras de opinión se refieren al tema de la inseguridad de modo similar y mediante una reiteración cotidiana ${ }^{16}$. En ese contexto, tal como ocurría en los años 90 con

15 Estudios sobre El Salvador, Guatemala y Honduras, que aplicaron en los últimos años programas de "mano dura", han fracasado en reducir los índices de delitos, e incluso en todos estos países las cifras de inseguridad se han incrementado, lo que muestra el fracaso de este tipo de planes ("Inseguridad: la clave está en lograr exclusión cero", nota de Bernardo Kliksberg, Clarín, 28/01/09).

16 Acerca de la función de los medios en la conformación de la opinión pública y en el reforzamiento de las opiniones existentes, véase, por ejemplo, Misas Arango (2005). las reformas neoliberales, el "bombardeo" constante del problema de la creciente inseguridad en los grandes medios, además de magnificar las proporciones del tema a partir de su repetición constante, hace parecer como si toda la población en su conjunto estuviese a favor del discurso de la "mano dura", reforzando este tipo de discurso reaccionario ${ }^{17}$. Tomando en cuenta este punto, no debería desdeñarse, entonces, la importancia crucial que adquieren figuras archi-conocidas y prestigiosas de los medios locales, como Susana Giménez, Mirtha Legrand, Moria Casán y Marcelo Tinelli, en la formación y conformación de una sólida opinión pública a favor de la "mano dura" y el discurso hegemónico de la biopolítica ${ }^{18}$. No parece casualidad, además, que resulten estos mismos artistas, que además disfrutan de altos grados de popularidad y prestigio popular, quienes han apoyado sin tapujos en los años 90 a figuras políticas que han contribuido en gran medida a llegar a esta situación sociocultural en la que vivimos actualmente. Es el caso especialmente del ex presidente Carlos Menem (1989 1999), símbolo de la aplicación de las políticas neoliberales y el incremento de la exclusión y marginalización de vastos sectores sociales ${ }^{19}$.

En lugar de abonar estas teorías reduccionistas y contrarias a todo respeto a la Constitución Nacional y la defensa y promoción de los derechos humanos ${ }^{20}$, tendríamos que recordar, por el

17 Por otra parte, al mismo tiempo que se hace hincapié en el delito estigmatizado de los pobres y el "peligro" que representan para el orden social, se minimiza, como señala Ragagnin, la gravedad del delito de "cuello blanco" generado por los sectores de mayor poder político y económico (ex funcionarios, empresarios, banqueros, etc.) (véase Ragagnin, 2005).

18 En los términos lacanianos, podemos decir que estas figuras, en el marco de la declinación de la Imago paterna, se transforman en nuevas figuras cuyo "ideal del yo" coincide con su mandato superyoico. En ese contexto, sus opiniones adquieren una notable valoración performativa para los ciudadanos.

19 Recuérdese, en ese sentido, que tanto Susana Giménez como Moria Casan apoyaron abiertamente al ex presidente durante la aplicación de las reformas de mercado de los años ' 90. Marcelo Tinelli, por su parte, brindó su programa de televisión "Videomatch" para que Menem cerrara su campaña electoral para las elecciones presidenciales de 1995, apoyándolo de manera indirecta al permitirle un amplio espacio mediático en la pantalla abierta en el que no recibió críticas políticas ni preguntas comprometedoras.

20 La Jueza de la Corte Suprema, Dra. Carmen Argibay, ha señalado 
contrario, que, según registros oficiales del 2006 del Sedronar, Secretaría de Programación para la prevención de la drogadicción y la lucha contra el narcotráfico, en Argentina existen 178.704 adictos a la pasta base residual de la cocaína (el "paco" ${ }^{\prime 2}$ ) y que, de ese total, el 68\% termina delinquiendo, ya que los propios efectos de la dosis de la droga les produce cambios en el organismo (euforia y satisfacción, luego disforia y fuerte deseo de consumo, junto con psicosis y paranoias que promueven la agresividad, para salir de la situación anterior de depresión y angustia), lo que los lleva a un circuito pulsional que, como lo abordara hace mucho Lacan (2006), busca retornar al consumo cíclico de droga como sea, además de volverlos violentos en sus métodos (Clarín, 15/03/09).

Pero, al mismo tiempo, debemos considerar también que sólo existen 2.500 camas en todo el país para asistir a los adictos y la mayoría de ellas está en clínicas privadas (Clarín, 15/03/09). A esta carencia se suma un nuevo problema estructural que consiste en la poca preparación que reciben los médicos y los propios hospitales para hacer frente a este problema, en muchos casos a partir de doctores y enfermeras paralizados por el miedo que les genera la violencia social de parte de los adictos. Por otra parte, debemos considerar también el fenomenal negociado que representa el narcotráfico y la connivencia que se genera con gran parte de la policía, incentivando la impunidad. Pero sobre todo, debemos insistir en analizar las causas y motivaciones más profundas y estruc-

recientemente su rechazo a la pena de muerte, señalando que "La Constitución de la República Argentina no permite la pena de muerte. Y cuando se empieza a pedir la pena de muerte lo que se está pidiendo es, sencillamente, que se viole la Constitución Nacional" (declaraciones citadas en Clarín, 08/03/09).

21 Según el Sedronar, el "Paco" es el nombre característico que adquiere una droga formada por pasta base cortada con otros productos de la elaboración de la cocaína (Clarín, 15/03/09). La invasión de este producto en la Argentina se remonta a la crisis del 2001-2002, en consonancia con el Plan Colombia de erradicación de drogas y la decisión del gobierno de México de prohibir la importación de los químicos que se usan para la elaboración de cocaína. Según el especialista Sebastián Cinquerri, este hecho llevó a los narcotraficantes a buscar nuevos lugares donde convertir la pasta base de cocaína en clorhidrato de exportación y para ello, acudieron a Argentina, Chile y Brasil, donde a partir de una presencia tercerizada, crearon la propia oferta para luego, a partir de su bajo precio, generar la demanda (Clarín, 15/03/09). turales que llevan a muchos sectores sociales a drogarse para delinquir, entre ellas, la falta de contención familiar y sobre todo, de contención y amparo social. La propia presidenta Cristina Fernández, ha señalado recientemente que "No se puede erradicar la inseguridad si no tenemos una sociedad más justa y equitativa, con empleo y educación" (Clarín, 12/03/09). Sin embargo, en la actualidad presenciamos un Estado que, en lugar de ocuparse de luchar con fuerza por erradicar la pobreza y la marginalidad social, lleva con su tibio accionar a que los jóvenes carenciados tengan una imagen negativa del Estado, a quienes asocian con la policía (especialmente, el patrullero policial) y la represión ${ }^{22}$. A su vez, la propia corrupción estructural de la policía y la impunidad de los crímenes de los sectores de mayor poder político y económico, llevan a potenciar aún más la imagen negativa del Estado y a exigir leyes más duras por parte de algunos sectores sociales reaccionarios, quienes, a su vez, se benefician política y económicamente de sus demandas de "mano dura". En ese contexto, se incrementa la potencia del discurso de sentido común a favor del Orden, mientras que los sectores carenciados, imposibilitados de una opción mejor para salir de manera individual de su situación, se ven obligados a reaccionar a la "violencia simbólica" y política que viene "desde arriba", mediante la violencia reactiva "desde abajo", lo que, finalmente, termina por acrecentar las demandas de mano dura" y hace del tema un círculo vicioso.

\section{A MODO DE CONCLUSIÓN}

\author{
Costumbres "salvajes", "eso no ocurre \\ en nuestro país", "no debería permitirse eso", \\ etc., y tantas reacciones groseras que traducen \\ ese mismo escalofrío, esa misma repulsión en \\ presencia de maneras de vivir, de creer, o de pensar \\ que nos son extrañas. De esta manera confundía \\ la Antigüedad todo lo que no participaba de
}

22 Como señala Kliksberg, citando el informe de Centroamérica sobre la aplicación (fracasada) de la política de "mano dura", "muchos de los jóvenes jamás han experimentado una interacción positiva con el Estado. Con frecuencia su única vivencia del Estado es la policía haciendo arrestos y encarcelando" (en Clarín, 28/01/09). 
la cultura griega (después greco-romana), con el mismo nombre de bárbaro. La civilización occidental ha utilizado después el término salvaje en el mismo sentido. Ahora bien, detrás de esos epitetos se disimula un mismo juicio: es posible que la palabra salvaje se refiera etimológicamente a la confusión e inarticulación del canto de los pájaros, opuestas al valor significante del lenguaje humano. Y salvaje, que quiere decir "del bosque", evoca también un género de vida animal, por oposición a la cultura humana. En ambos casos rechazamos admitir el mismo hecho de la diversidad cultural; preferimos expulsar de la cultura, a la naturaleza, todo lo que no se conforma a la norma según la cual vivimos. Esta actitud de pensamiento, en nombre de la cual excluimos a los "salvajes" (o a todos aquellos que hayamos decidido considerarlos como tales) de la humanidad, es justamente la actitud más marcante y la más distintiva de los salvajes mismos.

\section{Claude Levi Strauss,} Raza e Historia

En el transcurso de este trabajo nos propusimos desentrañar algunas de las falacias que definen el nuevo discurso hegemónico de la "mano dura". Este tipo de discurso no sólo peca de una lógica reduccionista y excesivamente simplificadora de la realidad, que hace hincapié en sus efectos inmediatos en lugar de sus múltiples causas, y de allí infiere que la solución son leyes más duras, sino que, en algunos casos más extremistas, se inserta dentro de una matriz reaccionaria que roza el racismo biopolítico, al exigir al Estado la eliminación lisa y llana de individuos que forman parte de la sociedad con el objeto explícito de mantener con vida al propio "cuerpo social" en "peligro". Como señala Ber- nardo Kliksberg, los países exitosos en materia de seguridad ciudadana no han sido los de "tolerancia cero" o "mano dura", sino más bien los que han aplicado la "exclusión cero". En efecto, las menores tasas de delincuencia no se encuentran en Estados Unidos o en América Latina, sino en países nórdicos como Noruega, Finlandia, Suecia y Dinamarca, donde, a pesar de tener el menor número de policías por habitante, se ha planeado desde el Estado una activa e integral política de inclusión social de los jóvenes carenciados (Clarín, 28/01/09). En estos países se ha mantenido un sólido Estado Benefactor que se ha ocupado y se ocupa de integrar sociocultural y económicamente al conjunto de los ciudadanos. Por el contrario, en la gran mayoría de los países de nuestra región, incluido, por supuesto, la Argentina, el Estado ha iniciado en las últimas décadas un proceso de desmantelamiento de sus funciones primordiales que ha promovido una inédita marginalización y desprotección de vastos sectores sociales. Sin embargo, a pesar del tiempo perdido, aún estamos a tiempo para comenzar un proyecto coherente e integral que plantee una inserción económica y social de estos jóvenes indefensos y resignados. Un proyecto serio y multidisciplinar que contribuya desde el Estado a una integración social del conjunto de la población, en lugar de pretender excluir y estigmatizar a aquellos que no han tenido la suerte de acceder a este "goteo" mítico de la riqueza del discurso neoliberal defendido por las elites económicas, y muchas veces se han visto obligados a buscar formas sustitutivas de suplir las carencias que debería brindarles el Estado, cayendo en el consumo de droga y en la delincuencia como única salida reactiva a la violencia social que les viene "desde arriba".

\section{REFERENCIAS BIBLIOGRÁFICAS}

Aboy Carlés, G. (2001). Las dos fronteras de la democracia argentina. La reformulación de las identidades políticas de Alfonsín a Menem. Rosario: Homo Sapiens.

Althusser, L. (1988). Ideología y aparatos ideológicos del Estado. En: La filosofía como arma de la revolución. México: Cuadernos de pasado y presente.

Austin, J. (1998). Cómo hacer cosas con palabras, Barcelona: Paidós. 
Barros, S. (2002). Orden, democracia y estabilidad. Discurso y política en la Argentina entre 1976 y 1991. Córdoba: Alción.

Bauman, Z. (2005). La globalización. Consecuencias humanas. Bs. As.: FCE.

Bourdieu, P. (1997). Sobre la televisión. Barcelona: Anagrama.

Bourdieu, P. (1999). Contrafuegos. Reflexiones para servir a la resistencia contra la invasión neoliberal. Barcelona: Anagrama.

Fair, H. (2009a). "El debate 'Nacionalismo sano' versus 'Patriotismo republicano'". En Revista Colección, № 20, Instituto de Ciencia Política y Relaciones Internacionales, Universidad Católica Argentina (UCA), Bs. As.

Fair, H. (2009b). "La elusión del síntoma social del capitalismo contemporáneo". En Revista Utopía y praxis latinoamericana. Revista Internacional de Filosofía Iberoamericana y Teoría social, 14 (46), julio-septiembre, Facultad de Ciencias Económicas y Sociales, Universidad del Zulia, Maracaibo, Venezuela.

Fair, H. (2010): "Una aproximación al pensamiento político de Michel Foucault", en Polis. Revista de Investigación Sociopolítica, Iztapalapa, México, Primer Semestre (en prensa).

Foucault, M. (1973). El orden del discurso. Barcelona: Tusquets.

Foucault, M. (1992). Genealogía del racismo. Madrid: La piqueta.

Foucault, M. (2003). Vigilar y castigar. Bs. As.: Siglo XXI.

Gramsci, A, (1977). Cuadernos de la cárcel. México: Juan Pablos editor.

Laclau, E. y Mouffe, C. (1987). Hegemonía y estrategia socialista. Hacia una radicalización de la democracia. Bs. As.: FCE.

Locke, J. (2000). Segundo tratado sobre el gobierno civil. Madrid: Alianza.

Lvovich, D. (2001). "La derecha argentina y las prácticas antisemitas". La derecha argentina. Nacionalistas, neoliberales, militares y clericales. Ed. S. McGee Deutsch. Bs. As.: Vergara.

Mastrini, G. y Becerra. M. (2006). Periodistas y Magnates. Estructura y concentración de las industrias culturales en América Latina, Bs. As.: Prometeo.

Misas Arango, G. (2005). La información en las sociedades contemporáneas. Revista de Economía Institucional, 7 (12).

Murillo, S. (2008). Colonizar el dolor. La interpelación ideológica del Banco Mundial en América Latina, Bs. As.: CLACSO.

O’Donnell, G. (1984). Democracia en la Argentina: Micro y Macro. En O. Oszlak, (Comp.). Proceso, crisis y transición democrática. Bs. As.: Centro Editor de América Latina.

Ragagnin, F. (2005). El relato de las noticias sobre delito de cuello blanco. La criminalidad de etiqueta, Palabra Clave, 13.

Ranciere, J. (1996). El desacuerdo. Política y filosofía, Bs. As.: Nueva Visión.

Sissa, G. (1968). El placer y el mal. Filosofía de la droga, Bs. As.: Manantial, 1968.

Solodkow, D. (2005). Racismo y Nación: Conflictos y (des)armonías identitarias en el proyecto nacional sarmientino, Decimonónica, 2 (1) 95-121. Disponible en http://www.decimononica.org/VOL_2.1/Solodkow_V2.1.pdf.

Traversa, E. (2003). La violencia nazi, Bs. As.: FCE.

Vega García, P. (1998). Legitimidad y representación en la crisis de la democracia actual. Barcelona: Working Papers. Zaffaroni, Carlos (2009): "Clases peligrosas". En Página 12, 13 de diciembre.

Zizek, S. (2002). ¿Quién dijo totalitarismo? Cinco intervenciones sobre el [malluso de una noción. Valencia: PreTextos. 